\title{
Impact of Renal Impairment on Intensive Blood-Pressure-Lowering Therapy and Outcomes in Intracerebral Hemorrhage
}

\author{
Results From ATACH-2
}

\begin{abstract}
Mayumi Fukuda-Doi, MD, MPH, PhD, Haruko Yamamoto, MD, PhD, Masatoshi Koga, MD, PhD, Yohei Doi, MD, PhD, Adnan I. Qureshi, MD, Sohei Yoshimura, MD, PhD, Kaori Miwa, MD, PhD, Akiko Ishigami, MD, Masayuki Shiozawa, MD, Katsuhiro Omae, PhD, Masafumi Ihara, MD, PhD, and Kazunori Toyoda, MD, PhD
\end{abstract}

Neurology ${ }^{\circledR}$ 2021;97:e913-e921. doi:10.1212/WNL.0000000000012442

\section{Abstract}

\section{Background and Objective}

The clinical effect of renal impairment on intracerebral hemorrhage (ICH) is unknown. This study sought to assess whether estimated glomerular filtration rate (eGFR) affects clinical outcomes or modifies the efficacy of intensive systolic blood pressure (BP) control (target, 110-139 mm Hg) against the standard (target, 140-179 mm Hg) among patients with ICH.

\section{Methods}

We conducted post hoc analyses of ATACH-2, a randomized, 2-group, open-label trial. The baseline eGFR of each eligible patient was calculated using the Chronic Kidney Disease Epidemiology Collaboration equation. The outcome of interest was death or disability at 90 days. Multivariate logistic regression models were used for analysis.

\section{Results}

Among the 1,000 patients randomized, 974 were analyzed. The median baseline eGFR was 88 (interquartile range, 68,99$) \mathrm{mL} / \mathrm{min} / 1.73 \mathrm{~m}^{2} ; 451(46.3 \%), 363(37.3 \%)$, and 160 (16.4\%) patients had baseline eGFR values of $\geq 90,60-89$, and $<60 \mathrm{~mL} / \mathrm{min} / 1.73 \mathrm{~m}^{2}$, respectively. Compared with normal eGFR $\left(\geq 90 \mathrm{~mL} / \mathrm{min} / 1.73 \mathrm{~m}^{2}\right)$, higher odds of death or disability were noted among those with eGFR values of $<60 \mathrm{~mL} / \mathrm{min} / 1.73 \mathrm{~m}^{2}$ (adjusted odds ratio [OR], 2.02; 95\% confidence interval [CI], 1.25-3.26) but not among those with eGFR values of $60-89 \mathrm{~mL} / \mathrm{min} / 1.73 \mathrm{~m}^{2}$ (OR, $1.01 ; 95 \% \mathrm{CI}, 0.70-1.46$ ). The odds of death or disability were significantly higher in the intensive arm among patients with decreased eGFR; the ORs were 0.89 (95\% CI, 0.55-1.44), 1.13 (0.68-1.89), and $3.60(1.47-8.80)$ in patients with eGFR values of $\geq 90,60-89$, and $<60 \mathrm{~mL} / \mathrm{min} / 1.73 \mathrm{~m}^{2}$, respectively ( $p$ for interaction $=0.02$ ).

\section{Discussion}

Decreased eGFR is associated with unfavorable outcomes following ICH. The statistically significant interaction between the eGFR group and treatment assignment raised safety concerns for the intensive BP-lowering therapy among patients with renal impairment.

\author{
Correspondence \\ Dr. Toyoda \\ toyoda@ncvc.go.jp
}

\section{MORE ONLINE}

III Class of Evidence

Criteria for rating

therapeutic and diagnostic

studies

NPub.org/coe

\section{Trial Registration Information}

Clinicaltrials.gov identifier: NCT01176565.

\footnotetext{
From the Departments of Cerebrovascular Medicine (M.F.-D., M.K., S.Y., K.M., A.I., M.S., K.T.), Data Science (M.F.-D., H.Y., K.O.), and Neurology (M.I.), National Cerebral and Cardiovascular Center; Department of Nephrology (Y.D.), Osaka University Graduate School of Medicine, Suita, Japan; Zeenat Qureshi Stroke Institute (A.I.Q.), St. Cloud, MN; and Department of Neurology (A.I.Q.), University of Missouri, Columbia.

Go to Neurology.org/N for full disclosures. Funding information and disclosures deemed relevant by the authors, if any, are provided at the end of the article. 


\section{Glossary}

$\mathbf{A E}=$ adverse event; AKI = acute kidney injury; ATACH-2 = Antihypertensive Treatment of Acute Cerebral Hemorrhage-2; $\mathbf{B P}=$ blood pressure; $\mathbf{C I}=$ confidence interval; $\mathbf{C K D}=$ chronic kidney disease; $\mathbf{e G F R}=$ estimated glomerular filtration rate; GCS = Glasgow Coma Scale; ICH = intracerebral hemorrhage; INTERACT2 = Second Intensive Blood Pressure Reduction in Acute Cerebral Haemorrhage Trial; IQR = interquartile range; IVH = intraventricular hemorrhage; $\mathbf{M D R D}=$ modification of diet in renal disease; MFPI = multivariable fractional polynomial interaction; $\mathbf{m R S}=$ modified Rankin Scale; NIHSS $=$ NIH Stroke Scale; $\mathbf{O R}$ = odds ratio; $\mathbf{S B P}$ = systolic blood pressure.

\section{Classification of Evidence}

This study provides Class II evidence that in spontaneous ICH, decreased eGFR identifies patients at risk of death or disability following intensive BP control.

Stroke and chronic kidney disease (CKD) are serious public health concerns. CKD, mainly characterized by a reduced estimated glomerular filtration rate (eGFR), is common among patients with stroke and is associated with unfavorable outcomes. $^{1-3}$

Intensive blood pressure (BP) lowering is a plausible therapeutic option for intracerebral hemorrhage (ICH); however, intensive BP control is controversial in patients with $\mathrm{CKD}$. According to some observational studies, $\mathrm{CKD}$ attenuates the beneficial effects of intensive systolic BP (SBP) control. ${ }^{4,5}$ The post hoc analysis of SPRINT (Systolic Blood Pressure Intervention Trial) reported that intensive BP control increases acute kidney injury (AKI) incidence and provides little or no cardiovascular benefit in patients with moderate to severe CKD.,7 These studies did not include patients with acute stroke. Among patients with ICH, INTERACT2 (Second Intensive Blood Pressure Reduction in Acute Cerebral Haemorrhage Trial) demonstrated that intensive SBP lowering yielded a modest improvement in functional outcomes compared with the standard; its post hoc analysis revealed that the effects of early intensive BP lowering were consistent across different eGFRs. Meanwhile, in the ATACH-2 study (Antihypertensive Treatment of Acute Cerebral Hemorrhage-II), which investigated the efficacy of intensive (target $110-139 \mathrm{~mm} \mathrm{Hg}$ ) vs standard (target $140-179 \mathrm{~mm} \mathrm{Hg}$ ) SBP-lowering initiated within 4.5 hours after symptom onset, intensive SBP-lowering therapy did not improve the functional outcomes but raised concerns for renal adverse events (AEs). The intensive treatment group had a twofold higher rate of renal AEs than the standard treatment group $(9.0 \% \text { vs } 4.0 \%)^{8}$

These findings suggest that the safety of intensive SBPlowering therapy in acute ICH remains a concern, especially among patients with CKD. Understanding the effect of renal function on clinical outcomes and treatment is crucial when selecting the target population of intensive SBP-lowering therapy. Using the ATACH-2 trial data, this study aimed to explore the effect of eGFR on clinical outcomes and its interaction with intensive BP-lowering treatment among patients with $\mathrm{ICH}$.

\section{Methods}

\section{Standard Protocol Approvals, Registrations, and Patient Consents}

ATACH-2 was registered in ClinicalTrials.gov (Unique identifier: NCT01176565). The institutional review board or the ethics committee at each participating site approved the ATACH-2 protocol, and all participants or their legally authorized representatives provided written informed consent.

\section{Classification of Evidence}

The primary research question was whether renal impairment affects clinical outcomes or modifies the efficacy of intensive SBP control in patients with intracerebral hemorrhage. This study provides Class II evidence that, in spontaneous ICH, decreased eGFR identifies patients at risk of death or disability following intensive BP control.

\section{Study Design}

ATACH-2 was an international, multicenter, randomized, 2-group, open-label, and blinded endpoint trial that examined the efficacy of intensive SBP lowering in patients with spontaneous supratentorial $\mathrm{ICH}$. The trial has been thoroughly described in a previous report. ${ }^{8}$ Briefly, patients with primary ICH of $<60 \mathrm{~mL}$ and SBP of $>180 \mathrm{~mm} \mathrm{Hg}$ upon hospital arrival within 4.5 hours of onset were randomly assigned to intensive (SBP: $110-139 \mathrm{~mm} \mathrm{Hg}$ ) or standard (SBP: $140-179 \mathrm{~mm} \mathrm{Hg}$ ) treatment. Meanwhile, those with a Glasgow Coma Scale (GCS) score of $<5$, prothrombin time international normalized ratio of $>1.5$ at presentation, or premorbid disability requiring assistance in ambulation or daily activities were excluded from the trial. The hourly minimum SBP of each patient was reduced to the assigned target range using IV nicardipine within 2 hours and maintained through 24 hours after randomization. 


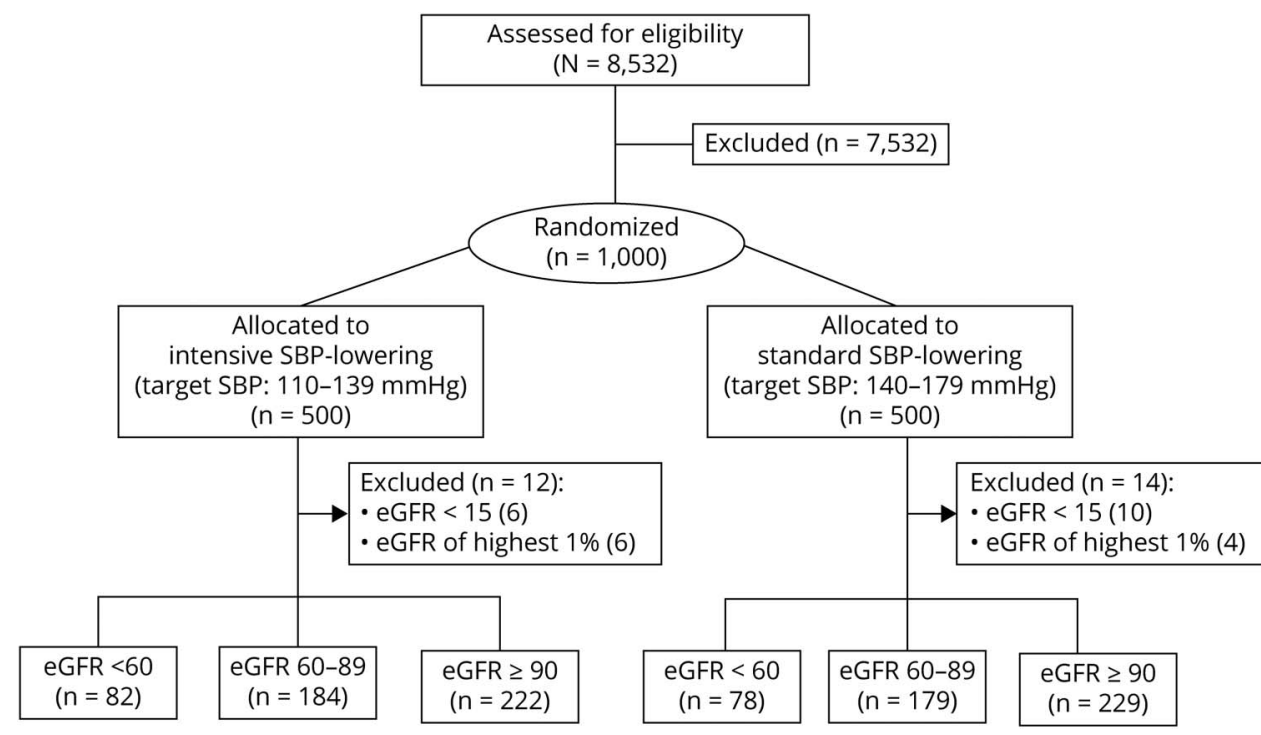

eGFR = estimated glomerular filtration rate; $\mathrm{SBP}=$ systolic blood pressure.

\section{Clinical Variables and Outcome Measures}

The primary outcome was a composite of death within 90 days or severe disability at 90 days, corresponding to modified Rankin Scale (mRS) score of 4-6 (hereafter referred to as death or disability). The secondary outcome was death within 90 days. Hematoma expansion was defined as an increase in volume ( $>6 \mathrm{~mL}$ or $>33 \%$ increase from the baseline) at CT conducted at 24 hours. Receiving surgical evacuation of hematoma was also treated as hematoma expansion. For each patient, creatinine values were obtained at baseline, 24, 48, and 72 hours after randomization. The baseline eGFR was calculated using the Chronic Kidney Disease Epidemiology Collaboration (CKD-EPI) equation. ${ }^{9}$ Patients were categorized into 3 groups according to their baseline eGFRs: $\geq 90,60-89$, and $<60 \mathrm{~mL} / \mathrm{min} / 1.73 \mathrm{~m}^{2}$, respectively. Patients with kidney failure $\left(\mathrm{eGFR}<15 \mathrm{~mL} / \mathrm{min} / 1.73 \mathrm{~m}^{2}\right)$ with or without renal replacement therapy were excluded. To avoid the leverage of extreme values, we also excluded those with the highest $1 \%$ of eGFR values. AKI was identified using the Kidney Disease: Improving Global Outcomes (KDIGO) criteria: $\geq 0.3 \mathrm{mg} / \mathrm{dL}$ within 48 hours or $>1.5$-fold increase in the serum creatinine level compared with that at baseline or preceding values. ${ }^{10}$

\section{Statistical Analysis}

The demographic and baseline clinical characteristics for categorical variables are presented as number (\%). Such characteristics were expressed as the mean (SD) for continuous variables with normal distribution and median (interquartile range $[\mathrm{IQR}]$ ) for those with skewed distribution. The baseline characteristics across the eGFR categories were compared using the $\chi^{2}$ test, analysis of variance, or Kruskal-Wallis test, as appropriate. The generalized linear mixed-effects model was used for identifying the differences in achieved SBP profiles per treatment and eGFR categories. The relationship between eGFR and clinical outcome was examined by multivariate logistic regression, and the outcome was presented as odds ratios (ORs) with 95\% confidence intervals (CIs). The potential nonlinear relationship between eGFR and the adjusted ORs of the outcome was illustrated by a restricted cubic splines curve with 3 knots. ${ }^{11,12}$ The treatment effects of BPlowering (intensive vs standard) were explored per eGFR by adding interaction terms to the logistic regression model. Potential interactions between treatment and eGFR as a continuous variable were investigated using the multivariable fractional polynomial interaction (MFPI) approach and illustrated by plotting the estimated ORs and 95\% CIs of outcomes according to the continuous eGFR level. $^{13}$

In these analyses, 2 models were employed to evaluate robustness. The models were adjusted for the following covariates selected a priori according to clinical knowledge: age (continuous), GCS score (continuous), presence of intraventricular hemorrhage (IVH) (dichotomized) (model 1), model 1 plus sex, treatment allocation (dichotomized), hematoma volume (continuous), and hematoma expansion (dichotomized) (model 2). Considering that we aimed to find the population with a potentially high risk for intensive treatment, we excluded hematoma expansion in the model to evaluate eGFR and treatment interaction.

The effect of AKI on the association between baseline eGFR and outcome or between treatment and outcome was identified by logistic regression using the interaction terms 
Table 1 Demographic and Clinical Characteristics

\begin{tabular}{|c|c|c|c|c|}
\hline & eGFR <60 (n = 160) & eGFR 60-89 (n = 363) & eGFR $\geq 90(n=451)$ & $p$ Value \\
\hline Age, y & $66 \pm 14$ & $65 \pm 14$ & $58 \pm 11$ & $<0.001$ \\
\hline Female & $61(38.1)$ & $135(37.2)$ & $178(39.5)$ & 0.8 \\
\hline Race, Asian & $48(30.1)$ & $168(47.1)$ & $330(73.8)$ & \\
\hline White & $69(44.5)$ & $141(39.5)$ & $72(16.1)$ & $<0.001$ \\
\hline Black & $37(23.8)$ & $45(12.6)$ & $44(9.8)$ & \\
\hline \multicolumn{5}{|l|}{ Medical history } \\
\hline Hypertension & $142(88.8)$ & $277(79.4)$ & $353(80.2)$ & 0.03 \\
\hline Dyslipidemia & $64(42.1)$ & $91(27.1)$ & $81(18.9)$ & $<0.001$ \\
\hline Diabetes mellitus & $55(34.8)$ & $54(15.1)$ & $70(15.6)$ & $<0.001$ \\
\hline Atrial fibrillation & $7(4.4)$ & $23(6.5)$ & $4(0.9)$ & $<0.001$ \\
\hline Stroke/TIA & $47(29.6)$ & $69(19.2)$ & $43(9.6)$ & $<0.001$ \\
\hline Antihypertensives & $115(72.8)$ & $187(52.1)$ & $178(39.6)$ & $<0.001$ \\
\hline Onset to randomization, $\min$ & $181 \pm 55$ & $188 \pm 56$ & $180 \pm 59$ & 0.37 \\
\hline Baseline GCS & $15(13-15)$ & $15(13-15)$ & $15(13-15)$ & 0.93 \\
\hline Baseline NIHSS & $11(6-16)$ & $11(6-16)$ & $11(7-15)$ & 0.98 \\
\hline \multicolumn{5}{|l|}{ Baseline CT findings } \\
\hline IVH & $46(28.9)$ & $105(29.2)$ & $102(22.9)$ & 0.09 \\
\hline Hematoma volume, $\mathrm{mL}$ & $8.1(3.9-16.5)$ & $9.6(4.8-18.7)$ & $10.9(5.6-18.7)$ & 0.04 \\
\hline Lobar hemorrhage & $23(14.6)$ & $56(15.4)$ & $34(7.5)$ & 0.001 \\
\hline Allocated to intensive SBP-lowering & $82(51.3)$ & $184(50.7)$ & $222(49.2)$ & 0.87 \\
\hline Hematoma expansion & $44(28.0)$ & $105(29.8)$ & $110(24.8)$ & 0.28 \\
\hline AKI & 37 (23.4) & $40(11.2)$ & 49 (10.9) & $<0.001$ \\
\hline
\end{tabular}

Abbreviations: AKI = acute kidney injury; eGFR = estimated glomerular filtration rate; GCS = Glasgow Coma Scale; IVH = intraventricular hemorrhage; NIHSS = $\mathrm{NIH}$ Stroke Scale; SBP = systolic blood pressure.

For categorical variables, $\mathrm{n}(\%)$ are presented with $\chi^{2} p$ value. For continuous variables, mean $\pm \mathrm{SD}$ (for parametric variables) or median (interquartile range) (for nonparametric variables) are presented with analysis of variance or Kruskal-Wallis $p$ values.

AKI-by-eGFR and AKI-by-treatment, respectively. Mediation analyses were conducted using a previously reported method. ${ }^{14}$

All missing data were handled in a listwise deletion manner. Multiple imputations were conducted as sensitivity analyses, accounting for any missing data, including outcome and covariates. We also used eGFR calculated using the modification of diet in renal disease (MDRD) equation to check the consistency of the results. ${ }^{15}$ Sensitivity analysis including all participants was conducted for completeness. All data were analyzed using STATA SE version 16 (STATA Corporation) or SAS university edition (SAS Institute Inc., 2020; sas.com/en_us/software/university-edition.html). Moreover, $p<0.10$ and $p<0.05$ were considered statistically significant for assessing the interaction and the main effects, respectively.

\section{Data Availability}

The ATACH-2 dataset is available to the public by request from the National Institute of Neurologic Disorders and Stroke. All data are de-identified.

\section{Results}

\section{Baseline Characteristics}

The flow diagram of this study is presented in Figure 1. Among 1,000 patients enrolled in ATACH-2, 974 were analyzed. The median baseline eGFR was 88 (IQR, 68-99) mL/ $\mathrm{min} / 1.73 \mathrm{~m}^{2}$. Among these patients, 451 (46.3\%), 363 (37.3\%), and 160 (16.4\%) had baseline eGFR values of $\geq 90$, $60-89$, and $<60 \mathrm{~mL} / \mathrm{min} / 1.73 \mathrm{~m}^{2}$, respectively. Among them, $38(4.0 \%)$ of the primary outcome, $22(2.3 \%)$ of hematoma expansion, and $9(0.9 \%)$ of IVH cases are missing; the missingness is similar across the eGFR subgroup. 
Figure 2 Mean Minimum Systolic Blood Pressure (SBP) Profile Grouped by Treatment and Estimated Glomerular Filtration Rate (eGFR) Category

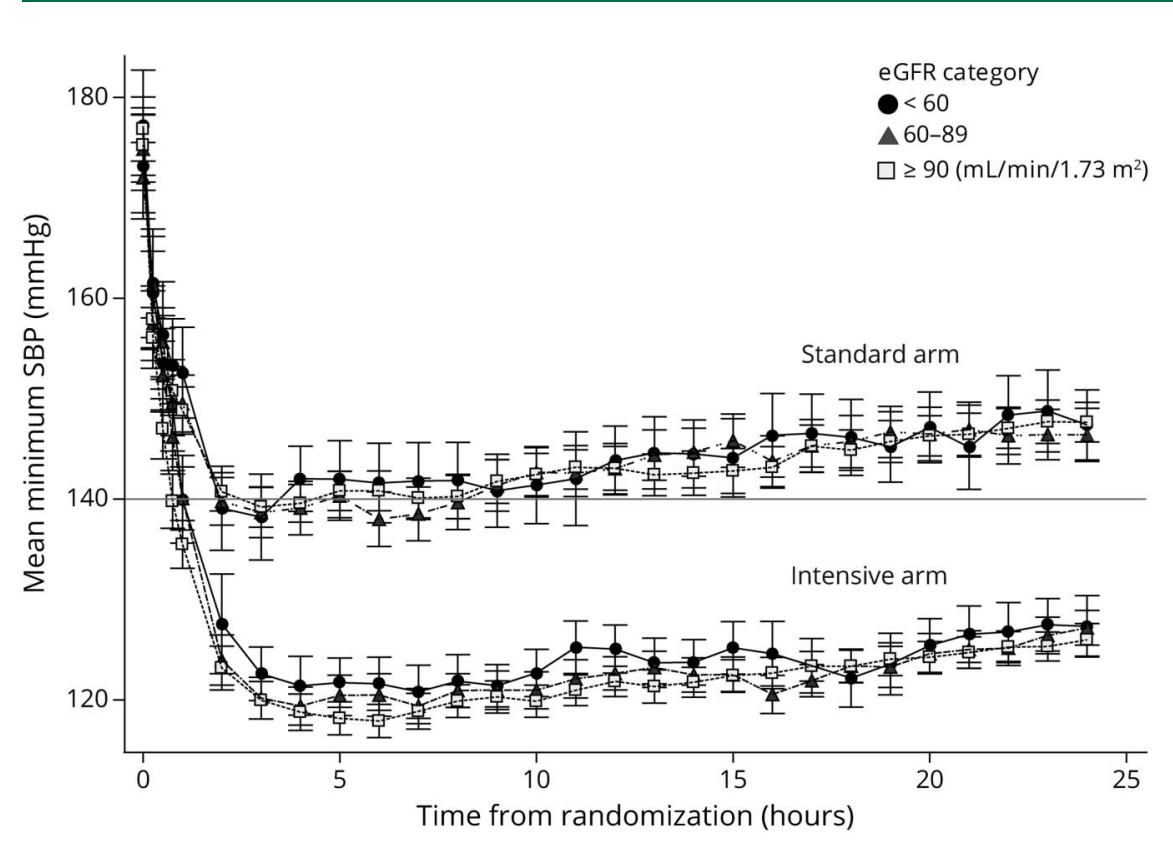

Patients' demographic and clinical characteristics by baseline eGFR category are displayed in Table 1 . Patients with decreased eGFR were older; more frequently had hypertension, dyslipidemia, atrial fibrillation, or diabetes mellitus; had more often been prescribed antihypertensive agents before the $\mathrm{ICH}$ onset; and were less frequently Asian than those with normal eGFR. Among the eGFR categories, baseline stroke severity, described by GCS or NIH Stroke Scale (NIHSS), was almost identical ( $p=0.93$, and $p=0.98$, respectively). Baseline hematoma volume was the least in the CKD group. The proportion of hematoma expansion after randomization was not significantly different, but the rate of AKI nearly doubled in the CKD group than in others; $23.4 \%, 11.2 \%$, and $10.9 \%$, for baseline eGFR of $<60,60-89$, and $\geq 90 \mathrm{~mL} / \mathrm{min} / 1.73 \mathrm{~m}^{2}$, respectively.

Figure 2 depicts the mean hourly minimum SBP profiles of intensive vs standard BP-lowering in each baseline eGFR category. In the intensive group, the SBP pattern is different among the 3 categories of eGFR $(p<0.01)$. Patients with decreased eGFR $\left(<60 \mathrm{~mL} / \mathrm{min} / 1.73 \mathrm{~m}^{2}\right)$ maintained a relatively higher SBP than the other patients.

Table 2 Association Between Baseline Estimated Glomerular Filtration Rate (eGFR) (mL/min/1.73 m²) Category and Clinical Outcome at 90 Days

\begin{tabular}{|c|c|c|c|c|c|c|c|}
\hline \multirow{2}{*}{$\begin{array}{l}\text { Outcome and } \\
\text { baseline eGFR }\end{array}$} & \multirow{2}{*}{$\begin{array}{l}\text { Number of } \\
\text { events }(\%)\end{array}$} & \multicolumn{2}{|l|}{ Crude } & \multicolumn{2}{|l|}{ Model 1} & \multicolumn{2}{|l|}{ Model 2} \\
\hline & & OR $(95 \% \mathrm{CI})$ & $p$ For trend & OR $(95 \% \mathrm{CI})$ & $p$ For trend & OR $(95 \% \mathrm{Cl})$ & $p$ For trend \\
\hline \multicolumn{8}{|c|}{ Death or disability } \\
\hline$\geq 90$ & $138 / 436(31.7)$ & Ref & $<0.01$ & Ref & 0.03 & Ref & 0.01 \\
\hline $60-89$ & $138 / 345$ (40.0) & $1.44(1.07-1.93)$ & & $1.06(0.75-1.49)$ & & $1.01(0.70-1.46)$ & \\
\hline$<60$ & $77 / 155$ (49.7) & $2.13(1.47-3.10)$ & & $1.72(1.12-2.64)$ & & $2.02(1.25-3.26)$ & \\
\hline \multicolumn{8}{|l|}{ Death } \\
\hline$\geq 90$ & $13 / 436(3.0)$ & Ref & $<0.01$ & Ref & 0.03 & Ref & 0.10 \\
\hline $60-89$ & $34 / 345$ (9.9) & $3.56(1.85-6.85)$ & & $2.15(1.06-4.36)$ & & $1.87(0.88-3.99)$ & \\
\hline$<60$ & 17/155 (11.0) & $4.01(1.90-8.46)$ & & $2.46(1.09-5.55)$ & & $2.08(0.86-5.05)$ & \\
\hline
\end{tabular}

Abbreviations: $\mathrm{Cl}$ = confidence interval; $\mathrm{OR}$ = odds ratio; ref = reference.

Model 1: adjusted for age, baseline Glasgow Coma Scale (GCS) score, and intraventricular hemorrhage (IVH). Model 2: adjusted for age, baseline GCS score, IVH, sex, initial hematoma volume, treatment allocation, and hematoma expansion. 


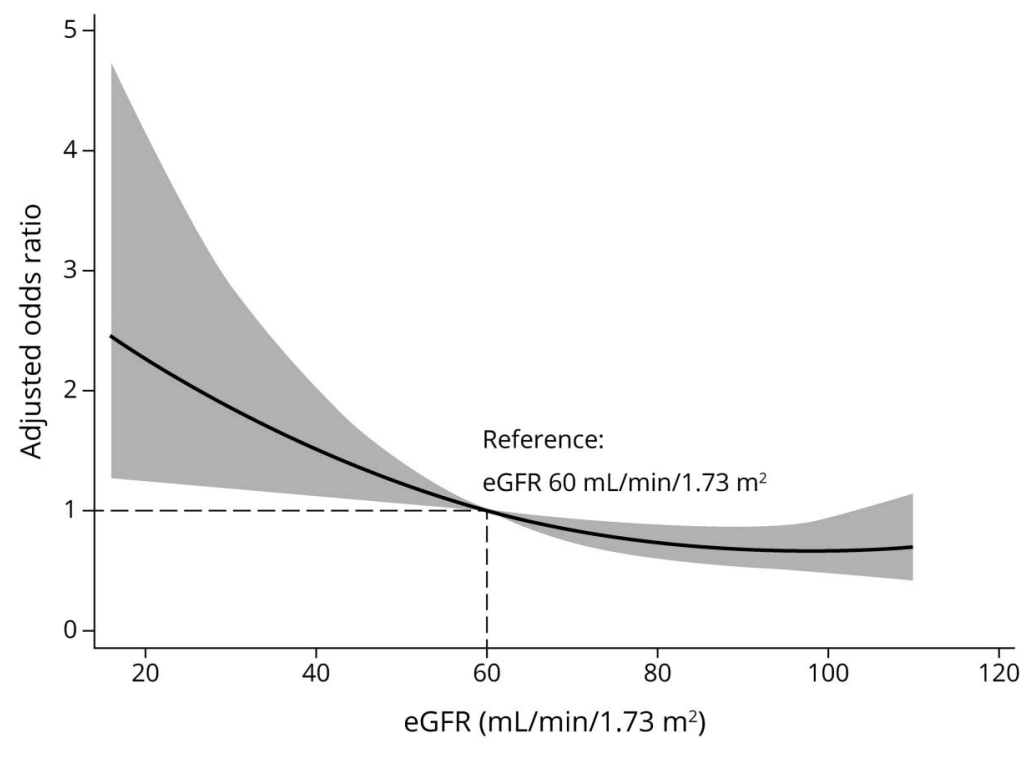

A restricted cubic splines curve with 3 knots illustrating the association of the baseline eGFR with odds ratios (solid line) and $95 \%$ confidence intervals (gray area). The model is adjusted for age, baseline Glasgow Coma Scale score, intraventricular hemorrhage, sex, initial hematoma volume, treatment allocation, and hematoma expansion. Reference value of eGFR: $60 \mathrm{~mL} / \mathrm{min} / 1.73 \mathrm{~m}^{2}$.

\section{Effect of Renal Impairment on Clinical Outcomes}

The rates of death or disability (mRS 4-6) were $31.7 \%, 40.0 \%$, and $49.7 \%$ in patients with baseline eGFR values of $\geq 90$, $60-89$, and $<60 \mathrm{~mL} / \mathrm{min} / 1.73 \mathrm{~m}^{2}$, respectively $(p<0.01)$. After adjustment, patients with decreased eGFR (eGFR $<60$ $\mathrm{mL} / \mathrm{min} / 1.73 \mathrm{~m}^{2}$ ) had higher odds of death or disability (adjusted ORs 1.72 [1.12-2.64] in model 1 and 2.02 [1.25-3.26] in model 2) than those with eGFR $\geq 90 \mathrm{~mL} / \mathrm{min} /$ $1.73 \mathrm{~m}^{2}$. However, the linear trend was not observed for eGFR categories in both models because the adjusted ORs in those with mildly decreased eGFR $\left(60-89 \mathrm{~mL} / \mathrm{min} / 1.73 \mathrm{~m}^{2}\right)$ crossed 1 . The association between eGFR category and death was not confirmed (Table 2).

Figure 3 displays the nonlinear relationship between baseline eGFR (as a continuous variable) and clinical outcomes. Herein, we set eGFR $=60 \mathrm{~mL} / \mathrm{min} / 1.73 \mathrm{~m}^{2}$ as the reference. If the eGFR was $<60 \mathrm{~mL} / \mathrm{min} / 1.73 \mathrm{~m}^{2}$, the OR of death or disability (mRS score 4-6) significantly increased. In sensitivity analyses using the MDRD equation or multiple imputations, the baseline eGFR had a similar relationship with the outcome (eTable $1 \mathrm{~A}$ and $1 \mathrm{~B}$, available from Dryad, doi.org/10.5061/dryad.d51c5b035).

Figure 4 Efficacy of Intensive Blood Pressure (BP)-Lowering According to Baseline Estimated Glomerular Filtration Rate (eGFR) (mL/min/1.73 m2) Categories

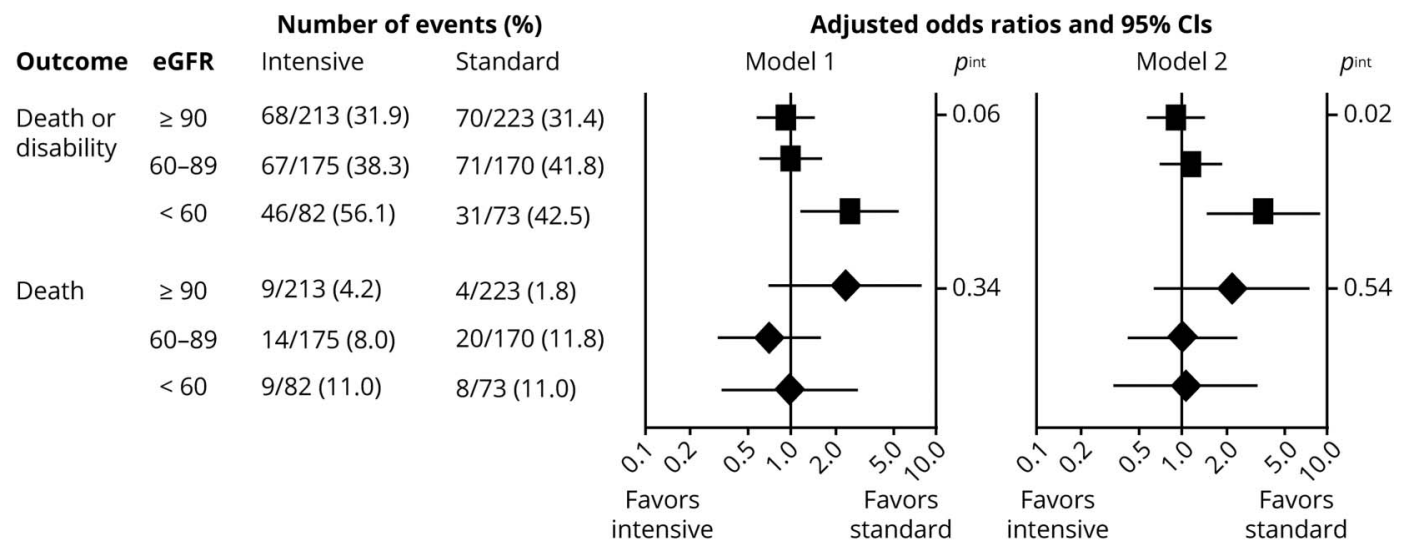

Adjusted odds ratios of death or disability (modified Rankin Scale score 4-6) and death among eGFR categories. Model 1: adjusted for age, baseline Glasgow Coma Scale (GCS) score, and intraventricular hemorrhage (IVH). Model 2: adjusted for age, baseline GCS score, IVH, sex, and initial hematoma volume. $p_{\text {int }}$ Represents $p$ values for interaction. $\mathrm{Cl}=$ confidence interval. 
Figure 5 Death or Disability Comparing Intensive Versus Standard Blood Pressure (BP)-Lowering by Baseline Estimated Glomerular Filtration Rate (eGFR) (mL/min/1.73 $\left.\mathrm{m}^{2}\right)$

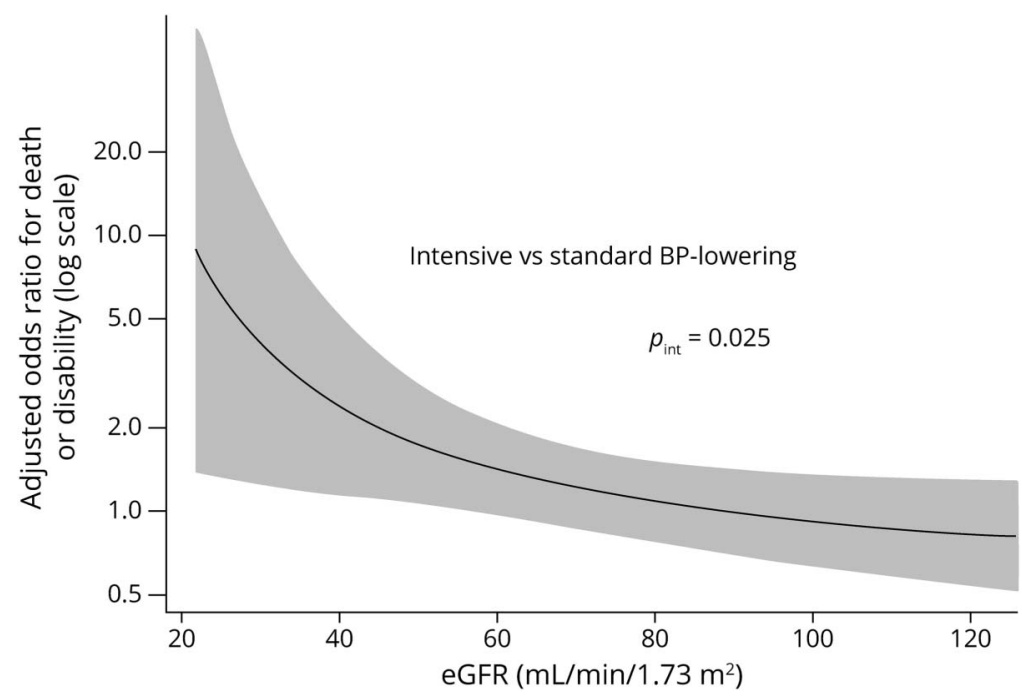

The multivariable fractional polynomial interaction plot shows the adjusted odds ratios (solid line) of death or disability (modified Rankin Scale score 4-6), comparing intensive vs standard BP-lowering therapies across the range of continuous values of baseline eGFR. The gray area shows $95 \%$ confidence intervals. Models were adjusted for age, baseline Glasgow Coma Scale score, intraventricular hemorrhage, sex, and initial hematoma volume. The $p$ value is for interaction between baseline eGFR and treatment effect.
Furthermore, when all patients were included, the results were similar (eTable 1C, available from Dryad, doi.org/ 10.5061/dryad.d51c5b035).

\section{Treatment Efficacy According to Baseline Renal Function}

The treatment-by-eGFR category interaction for death or disability in models 1 and 2 was statistically significant ( $p$ for interaction $=0.06$ and 0.02 , respectively), but not for death ( $p$ for interaction $=0.34$ and 0.54 , respectively) (Figure 4). In the fractional polynomial analysis, eGFR exhibited a nonlinear interaction effect ( $p$ for interaction $=0.041$ and 0.025 in models 1 and 2 , respectively). The ORs of death and disability were significantly increased in patients with decreased baseline eGFR undergoing intensive BP-lowering therapy (Figure 5). The results were consistent in sensitivity analyses using the MDRD equation (eTable 2A, available from Dryad, doi.org/10.5061/dryad.d51c5b035) and multiple imputations (eTable 2B, available from Dryad, doi.org/ $10.5061 /$ dryad.d51c5b035). When all patients were included in the analysis, we observed a similar trend (eTable 2C, available from Dryad, doi.org/10.5061/dryad. d51c5b035).

\section{Effect of AKI on the Treatment and Clinical Outcome}

AKI did not affect the association of baseline eGFR with death or disability ( $p$ for interaction $=0.55$ ) or of treatment with the outcome ( $p$ for interaction $=0.77$ ) in the study population. From the med4way procedure, AKI did not significantly mediate the association between treatment and death or disability (percentage mediated was $5 \%, p=0.98$ ) among the subgroup of patients with reduced eGFR (eGFR $<60 \mathrm{~mL}$ / $\min / 1.73 \mathrm{~m}^{2}$ ).

\section{Discussion}

In this post hoc analysis of ATACH-2, we describe the association of baseline eGFR with functional outcomes. After relevant clinical and demographic factors were adjusted, the eGFR on admission was independently associated with death or disability after ICH. The baseline eGFR modified the effect of intensive SBP-lowering. Intensive SBP-lowering therapy increased the risk of death or disability in patients with decreased baseline eGFR.

Previous studies support the association between decreased renal function and unfavorable outcomes after stroke. ${ }^{16-18}$ In another landmark clinical trial of ICH, INTERACT2, patients with decreased eGFR on admission had a high risk of poor functional outcomes. ${ }^{3,19}$ Our results are consistent with those of previous studies. The relationship between eGFR and functional outcomes was nonlinear. On the basis of the reference eGFR value $\left(60 \mathrm{~mL} / \mathrm{min} / 1.73 \mathrm{~m}^{2}\right)$, the risk of death or disability was significantly increased in patients with eGFR less than the reference value. However, it was consistent in those with eGFR $>60 \mathrm{~mL} / \mathrm{min} / 1.73 \mathrm{~m}^{2}$. The mechanism underlying the association between decreased eGFR and unfavorable outcomes is unknown. In our study, the initial NIHSS score and frequency of hematoma expansion were similar among baseline eGFR categories (Table 1). The possible explanations include an increased cerebrovascular risk due to shared vascular risk factors, such as hypertension, diabetes, and dyslipidemia, ${ }^{2}$ as well as CKD-specific pathophysiologic mechanisms, including coagulation disorders, endothelial dysfunction, chronic inflammation, and oxidative stress. ${ }^{2,20}$ A higher incidence of cognitive impairment, depression, and sarcopenia in patients with CKD may affect functional recovery following $\mathrm{ICH}^{20-22}$ 
Another critical point is therapeutic dilemmas for patients with CKD. Generally, maintaining the balance between high bleeding risk and high thromboembolic risk in patients with $\mathrm{CKD}$ is difficult for clinicians. ${ }^{2}$ Some therapeutic or diagnostic procedures, such as coronary angiography, may be paused because of renal toxicity risk (e.g., contrast-induced nephropathy). ${ }^{23,24}$ These dilemmas may lead to therapeutic nihilism; therefore, cardiovascular diseases are frequently underdiagnosed and undertreated in patients with $\mathrm{CKD}$. ${ }^{23,25}$ In this study, the mean BP achieved in patients with decreased eGFR was slightly higher than that achieved in others in the intensive arm, reflecting not just the potential therapeutic resistance to nicardipine but the possible psychological resistance of clinicians against excessive $\mathrm{BP}$ reduction arising from the concerns of renal toxicity.

Renal impairment itself can modify the treatment effect in acute stroke. In our study, the intensive SBP-lowering increased the risk of death or disability among patients with decreased eGFR; meanwhile, in the post hoc analysis of INTERACT2, decreased eGFR did not modify the treatment effect of intensive SBP-lowering. ${ }^{3}$ The critical differences in the 2 trials are the baseline and achieved SBP levels and the antihypertensive regimen used for SBP control. In ATACH-2, all patients had an initial SBP $\geq 180 \mathrm{~mm} \mathrm{Hg}$; meanwhile, only $48 \%$ of the patients presented at the same level of SBP in INTERACT2. Subsequently, in ATACH-2, SBP was more rapidly and strictly reduced using IV nicardipine. Therefore, the achieved SBP was substantially lower in ATACH-2 than in INTERACT2. It is well-known that the ability to autoregulate the glomerular filtration rate in renal hypoperfusion (e.g., rapid SBP fall) is prone to be impaired in patients with $\mathrm{CKD}^{26}$ In fact, AKI was highly prevalent among those with decreased eGFR on admission $(p<0.001$, Table 1$)$; renal events are not explicitly reported in INTERACT2 or the pooled analysis of the 2 trials. ${ }^{27}$ Because AKI may lead to poor cardiovascular outcomes, independent of or in conjunction with the CKD-related risks, ${ }^{28,29}$ we performed the mediation analysis to test whether AKI mediates between intensive SBP control and poor outcomes in patients with reduced eGFR. As a result, AKI was not the mediator between treatment and poor outcomes but the predictor for poor outcomes, as already reported in the entire ATACH-2 population. ${ }^{30}$ In this context, because the brain and kidneys share similar susceptibility to vascular injury, ${ }^{20,31}$ patients with decreased eGFR may be more susceptible to restricted cerebral perfusion by aggressive SBP lowering, resulting in delayed functional recovery. However, further studies are warranted to elucidate the mechanism.

Methodologically, the 2 studies are different in the manner of treating the eGFR value. In our study, given the potential nonlinear relationship between eGFR and outcome or treatment effect, ${ }^{11,12}$ a restricted cubic spline model and the MFPI approach were used aside from eGFR categorization. These approaches may contribute to preserving the statistical power to detect meaningful differences. ${ }^{13}$
This study has some limitations. First, in the trial setting, we excluded some patients with typical ICH exhibiting more severe symptoms such as massive hematoma $\left(\geq 60 \mathrm{~cm}^{3}\right)$ or poor premorbid functional status, thereby limiting generalizability. Second, information regarding renal function such as proteinuria or eGFR value before the ICH onset was unavailable. Considering that serum creatinine is affected by acute illness, ${ }^{32}$ using this marker on admission, for reference, can be misleading. Third, we excluded 26 patients with extreme eGFR values. Patients with end-stage renal disease (eGFR $<15 \mathrm{~mL} / \mathrm{min} / 1.73 \mathrm{~m}^{2}$ ) were excluded because the effect of intensive SBP-lowering on clinical outcomes may be different in this population..$^{33,34}$ We also excluded extremely high eGFR $\left(\geq 127 \mathrm{~mL} / \mathrm{min} / 1.73 \mathrm{~m}^{2}\right)$ because it may represent those with reduced muscle mass, such as the elderly, frail, and patients with other chronic muscle diseases, rather than actual renal function. ${ }^{32}$ Our sensitivity analysis including those with extremely high eGFR values did not affect the interaction effects. Fourth, several subanalyses of ATACH-2 have been completed. Considering the hypothesis-generating nature of post hoc analysis, careful interpretation is advised on any statistically significant findings due to multiple testing.

This post hoc analysis of ATACH-2 revealed that decreased eGFR was associated with death or disability after ICH. Furthermore, eGFR significantly modified the risk of intensive SBP-lowering in acute ICH, and intensive SBPlowering is potentially harmful among patients with decreased eGFR. Further studies are required to address the optimal SBP target according to the baseline eGFR.

\section{Acknowledgement}

The authors thank Professor Yuko Y. Palesch for statistical advice.

\section{Study Funding}

This study is supported by grants from the National Institute of Neurological Disorders and Stroke (NINDS; U01-NS062091, U01-NS061861, U01-NS059041), Japan Agency for Medical Research and Development (AMED; 20lk0201094h0002, 20lk0201109h0001), and the Ministry of Education, Culture, Sports, Science and Technology (MEXT; Funds for the Development of Human Resources in Science and Technology, Initiative for Realizing Diversity in the Research Environment).

\section{Disclosure}

K. Toyoda reports personal fees from Daiichi Sankyo, Bayer Yakuhin, Bristol Myers Squibb, Takeda, and Nippon Boehringer Ingelheim, outside the submitted work. M. Koga reports personal fees from Bayer Yakuhin, Otsuka, Daiichi Sankyo, NBI, and Ono; and grants from Takeda, DaiichiSankyo, NBI, and Shionogi, outside the submitted work. M. Ihara reports personal fees from Daiichi Sankyo, Eisai, and Bayer; and grants from Panasonic, Bristol-Myers Squibb, and Otsuka Pharmaceutical, outside the submitted work. The other authors report no disclosures relevant to the manuscript. Go to Neurology.org/ $\mathrm{N}$ for full disclosures. 


\section{Publication History}

Received by Neurology January 20, 2021. Accepted in final form May 27, 2021.

Appendix Authors

\begin{tabular}{lll}
\hline Name & Location & Contribution \\
\hline Mayumi & National Cerebral and & Execution of ATACH-2; \\
$\begin{array}{l}\text { Fukuda-Doi, } \\
\text { MD, MPH, PhD }\end{array}$ & Cardiovascular Center, & $\begin{array}{l}\text { designed and conceptualized } \\
\text { Suita, Japan }\end{array}$ \\
& & $\begin{array}{l}\text { the present study; analyzed th } \\
\text { datafted the manuscript } \\
\text { for intellectual content }\end{array}$
\end{tabular}

\begin{tabular}{lll}
\hline Haruko & National Cerebral and & Execution of ATACH-2; \\
Yamamoto, & Cardiovascular Center, & $\begin{array}{l}\text { interpreted the data; revised } \\
\text { the manuscript for intellectua } \\
\text { MD, PhD }\end{array}$ \\
Suita, Japan & $\begin{array}{l}\text { content } \\
\end{array}$
\end{tabular}

Masatoshi National Cerebral and Execution of ATACH-2; revised

Koga, MD, PhD Cardiovascular Center, the manuscript for intellectual Suita, Japan content

\begin{tabular}{ll}
\hline Yohei Doi, MD, & Osaka University \\
PhD & Graduate School of \\
& Medicine, Suita, Japan
\end{tabular}

Design of the present study; interpreted the data; revised the manuscript for intellectual content

Adnan I. Zeenat Qureshi Stroke

Execution, conception, and

Qureshi, MD Institute, St. Cloud, MN design of ATACH-2; revised the manuscript for intellectual content

\begin{tabular}{lll}
\hline $\begin{array}{l}\text { Sohei } \\
\text { Yoshimura, } \\
\text { MD, PhD }\end{array}$ & $\begin{array}{l}\text { National Cerebral and } \\
\text { Cardiovascular Center, } \\
\text { Suita, Japan }\end{array}$ & $\begin{array}{l}\text { Execution of ATACH-2; revised } \\
\text { the manuscript for intellectual } \\
\text { content }\end{array}$ \\
\hline $\begin{array}{l}\text { Kaori Miwa, } \\
\text { MD, PhD }\end{array}$ & $\begin{array}{l}\text { National Cerebral and } \\
\text { Cardiovascular Center, } \\
\text { Suita, Japan }\end{array}$ & $\begin{array}{l}\text { Execution of ATACH-2; revised } \\
\text { the manuscript for intellectual } \\
\text { content }\end{array}$ \\
\hline $\begin{array}{l}\text { Akiko } \\
\text { Ishigami, MD }\end{array}$ & $\begin{array}{l}\text { National Cerebral and } \\
\text { Cardiovascular Center, } \\
\text { Suita, Japan }\end{array}$ & $\begin{array}{l}\text { Execution of ATACH-2; revised } \\
\text { the manuscript for intellectual } \\
\text { content }\end{array}$ \\
\hline $\begin{array}{l}\text { Masayuki } \\
\text { Shiozawa, MD }\end{array}$ & $\begin{array}{l}\text { National Cerebral and } \\
\text { Cardiovascular Center, } \\
\text { Suita, Japan }\end{array}$ & $\begin{array}{l}\text { Execution of ATACH-2; revised } \\
\text { the manuscript for intellectual } \\
\text { content }\end{array}$ \\
\hline $\begin{array}{l}\text { Katsuhiro } \\
\text { Omae, PhD }\end{array}$ & $\begin{array}{l}\text { National Cerebral and } \\
\text { Cardiovascular Center, } \\
\text { Suita, Japan }\end{array}$ & $\begin{array}{l}\text { Interpreted the data; revised } \\
\text { the manuscript for intellectual } \\
\text { content }\end{array}$ \\
\hline $\begin{array}{l}\text { Masafumi } \\
\text { Ihara, MD, PhD }\end{array}$ & $\begin{array}{l}\text { National Cerebral and } \\
\text { Cardiovascular Center, } \\
\text { Suita, Japan }\end{array}$ & $\begin{array}{l}\text { Execution of ATACH-2; revised } \\
\text { the manuscript for intellectual } \\
\text { content }\end{array}$ \\
\hline $\begin{array}{l}\text { Kazunori } \\
\text { Toyoda, MD, } \\
\text { PhD }\end{array}$ & $\begin{array}{l}\text { National Cerebral and } \\
\text { Cardiovascular Center, } \\
\text { Suita, Japan }\end{array}$ & $\begin{array}{l}\text { Execution of ATACH-2; } \\
\text { designed and conceptualized } \\
\text { the present study; revised the } \\
\text { manuscript for intellectual } \\
\text { content }\end{array}$ \\
& & \\
& &
\end{tabular}

\section{References}

1. El Husseini N, Fonarow GC, Smith EE, et al. Renal dysfunction is associated with poststroke discharge disposition and in-hospital mortality: findings from get with the guidelines-stroke. Stroke. 2017;48(2):327-334.

2. Toyoda K, Ninomiya T. Stroke and cerebrovascular diseases in patients with chronic kidney disease. Lancet Neurol. 2014;13(8):823-833.

3. Zheng D, Sato S, Arima H, et al. Estimated GFR and the effect of intensive blood pressure lowering after acute intracerebral hemorrhage. Am J Kidney Dis. 2016;68(1): 94-102.

4. Kovesdy CP, Bleyer AJ, Molnar MZ, et al. Blood pressure and mortality in U.S. veterans with chronic kidney disease: a cohort study. Ann Intern Med. 2013;159(4):233-242.
5. Kovesdy CP, Lu JL, Molnar MZ, et al. Observational modeling of strict vs conventional blood pressure control in patients with chronic kidney disease. JAMA Intern Med. 2014;174(9):1442-1449.

6. Group SR, Wright JT Jr, Williamson JD, et al. A randomized trial of intensive versus standard blood-pressure control. N Engl J Med. 2015;373(22):2103-2116.

7. Obi Y, Kalantar-Zadeh K, Shintani A, Kovesdy CP, Hamano T. Estimated glomerular filtration rate and the risk-benefit profile of intensive blood pressure control amongst nondiabetic patients: a post hoc analysis of a randomized clinical trial. J Intern Med. 2018;283(3):314-327.

8. Qureshi AI, Palesch YY, Barsan WG, et al. Intensive blood-pressure lowering in patients with acute cerebral hemorrhage. N Engl J Med. 2016;375(11):1033-1043.

9. Levey AS, Stevens LA, Schmid $\mathrm{CH}$, et al. A new equation to estimate glomerular filtration rate. Ann Intern Med. 2009;150(9):604-612.

10. KDIGO Group. KDIGO clinical practice guideline for acute kidney injury. Kidney Int Suppl. 2012;2(1).

11. Chronic Kidney Disease Prognosis C, Matsushita K, van der Velde M, et al. Association of estimated glomerular filtration rate and albuminuria with all-cause and cardiovascular mortality in general population cohorts: a collaborative meta-analysis. Lancet. 2010;375(9731):2073-2081.

12. van der Velde M, Matsushita K, Coresh J, et al. Lower estimated glomerular filtration rate and higher albuminuria are associated with all-cause and cardiovascular mortality: a collaborative meta-analysis of high-risk population cohorts. Kidney Int. 2011;79(12): 1341-1352.

13. Royston P, Sauerbrei W. A new approach to modelling interactions between treatment and continuous covariates in clinical trials by using fractional polynomials. Stat Med. 2004;23(16):2509-2525.

14. Discacciati A, Bellavia A, Lee JJ, Mazumdar M, Valeri L. Med4way: a Stata command to investigate mediating and interactive mechanisms using the four-way effect decomposition. Int J Epidemiol. 2018;16.

15. Levey AS, Coresh J, Greene T, et al. Using standardized serum creatinine values in the modification of diet in renal disease study equation for estimating glomerular filtration rate. Ann Intern Med. 2006;145(4):247-254.

16. Miyagi T, Koga M, Yamagami H, et al. Reduced estimated glomerular filtration rate affects outcomes 3 months after intracerebral hemorrhage: the stroke acute management with urgent risk-factor assessment and improvement-intracerebral hemorrhage study. J Stroke Cerebrovasc Dis. 2015;24(1):176-182.

17. You S, Shi L, Zhong C, et al. Prognostic significance of estimated glomerular filtration rate and cystatin $\mathrm{C}$ in patients with acute intracerebral hemorrhage. Cerebrovasc Dis. 2016;42(5-6):455-463.

18. Beuscher VD, Sprugel MI, Gerner ST, et al. Chronic kidney disease and clinical outcomes in patients with intracerebral hemorrhage. J Stroke Cerebrovasc Dis. 2020; 29(8):104802.

19. Anderson CS, Heeley E, Huang Y, et al. Rapid blood-pressure lowering in patients with acute intracerebral hemorrhage. $N$ Engl J Med. 2013;368(25):2355-2365.

20. Lu R, Kiernan MC, Murray A, Rosner MH, Ronco C. Kidney-brain crosstalk in the acute and chronic setting. Nat Rev Nephrol. 2015;11(12):707-719.

21. Hedayati SS, Minhajuddin AT, Toto RD, Morris DW, Rush AJ. Prevalence of major depressive episode in CKD. Am J Kidney Dis. 2009;54(3):424-432.

22. Moorthi RN, Avin KG. Clinical relevance of sarcopenia in chronic kidney disease. Curr Opin Nephrol Hypertens. 2017;26(3):219-228.

23. Gansevoort RT, Correa-Rotter R, Hemmelgarn BR, et al. Chronic kidney disease and cardiovascular risk: epidemiology, mechanisms, and prevention. Lancet. 2013; 382(9889):339-352.

24. Charytan DM, Setoguchi S, Solomon DH, Avorn J, Winkelmayer WC. Clinical presentation of myocardial infarction contributes to lower use of coronary angiography in patients with chronic kidney disease. Kidney Int. 2007;71(9):938-945.

25. Fox CS, Muntner P, Chen AY, et al. Use of evidence-based therapies in short-term outcomes of ST-segment elevation myocardial infarction and non-ST-segment elevation myocardial infarction in patients with chronic kidney disease: a report from the National Cardiovascular Data Acute Coronary Treatment and Intervention Outcomes Network registry. Circulation. 2010;121(3):357-365.

26. Abuelo JG. Normotensive ischemic acute renal failure. N Engl J Med. 2007;357(8): 797-805.

27. Moullaali TJ, Wang X, Martin RH, et al. Blood pressure control and clinical outcomes in acute intracerebral haemorrhage: a preplanned pooled analysis of individual participant data. Lancet Neurol. 2019;18(9):857-864.

28. Chawla LS, Eggers PW, Star RA, Kimmel PL. Acute kidney injury and chronic kidney disease as interconnected syndromes. N Engl J Med. 2014;371(1):58-66.

29. Burgess LG, Goyal N, Jones GM, et al. Evaluation of acute kidney injury and mortality after intensive blood pressure control in patients with intracerebral hemorrhage. J Am Heart Assoc. 2018;7(8).

30. Qureshi AI, Huang W, Lobanova I, et al. Systolic blood pressure reduction and acute kidney injury in intracerebral hemorrhage. Stroke. 2020;51:3030-3038.

31. Ito S, Nagasawa T, Abe M, Mori T. Strain vessel hypothesis: a viewpoint for linkage of albuminuria and cerebro-cardiovascular risk. Hypertens Res. 2009;32(2):115-121.

32. Stevens LA, Coresh J, Greene T, Levey AS. Assessing kidney function: measured and estimated glomerular filtration rate. $N$ Engl J Med. 2006;354(23):2473-2483.

33. Hannedouche T, Roth H, Krummel T, et al. Multiphasic effects of blood pressure on survival in hemodialysis patients. Kidney Int. 2016;90(3):674-684.

34. Turner JM, Peixoto AJ. Blood pressure targets for hemodialysis patients. Kidney Int. 2017;92(4):816-823. 


\section{Neurology}

\section{Impact of Renal Impairment on Intensive Blood-Pressure-Lowering Therapy and Outcomes in Intracerebral Hemorrhage: Results From ATACH-2 \\ Mayumi Fukuda-Doi, Haruko Yamamoto, Masatoshi Koga, et al. \\ Neurology 2021;97;e913-e921 Published Online before print July 1, 2021}

DOI 10.1212/WNL.0000000000012442

This information is current as of July 1, 2021

\section{Updated Information \&} Services

\section{References}

Subspecialty Collections

Permissions \& Licensing

Reprints including high resolution figures, can be found at: http://n.neurology.org/content/97/9/e913.full

This article cites 31 articles, 2 of which you can access for free at: http://n.neurology.org/content/97/9/e913.full\#ref-list-1

This article, along with others on similar topics, appears in the following collection(s):

Class II

http://n.neurology.org/cgi/collection/class_ii

Clinical trials Randomized controlled ( $\overline{\mathbf{C}}$ ONSORT agreement)

http://n.neurology.org/cgi/collection/clinical_trials_randomized_contro lled_consort_agreement

Intracerebral hemorrhage

http://n.neurology.org/cgi/collection/intracerebral_hemorrhage

Information about reproducing this article in parts (figures,tables) or in its entirety can be found online at:

http://www.neurology.org/about/about_the_journal\#permissions

Information about ordering reprints can be found online:

http://n.neurology.org/subscribers/advertise

Neurology ${ }^{\circledR}$ is the official journal of the American Academy of Neurology. Published continuously since 1951, it is now a weekly with 48 issues per year. Copyright Copyright ( 2021 The Author(s). Published by Wolters Kluwer Health, Inc. on behalf of the American Academy of Neurology.. All rights reserved. Print ISSN: 0028-3878. Online ISSN: 1526-632X.

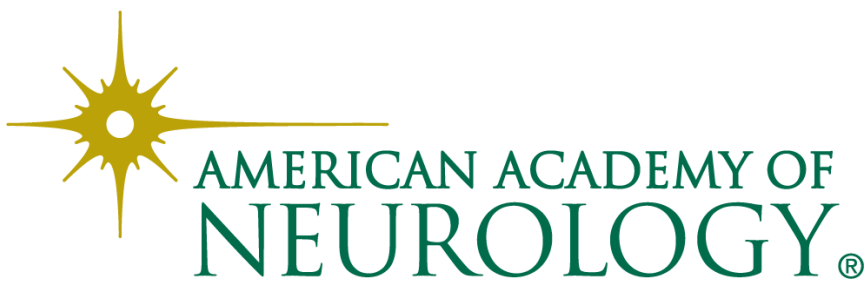

